\title{
KEZIAH MASON: A BRUXA CIENTISTA DE H. P. LOVECRAFT
}

\author{
KEZIAH MASON: H. P. LOVECRAFT'S SCIENTIST WITCH
}

Nathalia Sorgon Scotuzzi ${ }^{1}$ 
RESUMO: A obra do escritor norte-americano H. P. Lovecraft é marcada por um conteúdo mitológico de autoria própria que é parte indissociável de sua escrita. Essa mitologia autêntica e alienígena possui seus próprios pressupostos, não tendo relações diretas (e poucas vezes indiretas) com a mitologia cristã. O conto "Sonhos na casa da bruxa" (1933), entretanto, trabalha com a figura da bruxa, que é constantemente associada ao Diabo e ao Cristianismo. Assim, nosso objetivo com esse trabalho é identificar de que forma Lovecraft desenvolve essa figura nessa história e até que ponto incorpora elementos da mitologia cristã nela. A principal base teórica para o presente artigo é o estudo de Silvia Federici a respeito das bruxas; deste estudo e outros, elencaremos características históricas da bruxaria que serão identificadas no texto de Lovecraft, sendo reafirmadas ou contestadas. Por fim, mostraremos que a personagem do autor norte-americano é uma das poucas personagens femininas em toda sua obra, sendo uma tentativa de apresentar uma nova versão da bruxa, porém sem conseguir fugir de estereótipos negativos.

PALAVRAS-CHAVE: H. P. Lovecraft; Bruxa; Cristianismo; Bruxaria.

ABSTRACT: The work of the American writer H. P. Lovecraft is characterized by a mythological content of his own creation which is inseparable from his writings. This authentic and alien mythology has its own premises, not having direct (and few indirect) relations to the Christian mythology. The short story "The Dreams in the Witch House" (1933), however, works with the figure of the witch, who is constantly associated with the devil and with Christianism and, thus, our goal with this work is to identify how Lovecraft designs this character in this short story and to which extent he incorporates elements of the Christian mythology in it. The main theoretical basis for this paper is Silvia Federeici's study on witches; from this work and others, we will draw historical characteristics of witchcraft that can be identified in Lovecraft's text, being either acknowledged or contradicted. At last, we will show that the author's character is one of the few female characters in all of his work, being an attempt to present a new version of a witch, but not being able to escape negative stereotypes.

KEYWORDS: H. P. Lovecraft; Witch; Christianism; Witchcraft. 


\section{A BRUXA NO IMAGINÁRIO OCIDENTAL}

A bruxa, atualmente, é uma figura bastante marcada por estereótipos e que sofreu grandes mudanças em suas características durante os séculos que se passaram entre a Idade Média e os dias de hoje. Sobre sua origem, ou ainda, sobre quem foram as primeiras bruxas, existem diferentes possíveis versões; é um assunto até hoje em aberto e passível de contestação, mas remete à antiguidade. Independentemente de quais foram suas origens, há o fato de que a mulher, apenas por ser mulher, possui um estigma na sociedade ocidental. Isso se dá devido às diversas situações e condições que se relacionam ao seu corpo e habilidades. Muitas vezes, na cultura medieval e mesmo antes dela, a mulher era vista como um ser de maior conexão com a natureza, capaz de gerar uma vida, e isso podia se tornar motivo de grande apreensão. De acordo com Jean Delumeau: "Porque mais próxima da natureza e mais bem informada de seus segredos, a mulher sempre foi creditada, nas civilizações tradicionais, do poder não só de profetizar, mas também de curar ou de prejudicar por meio de misteriosas receitas" (1989, p. 311). Toda essa capacidade de poder fez com que o homem, em uma reação de medo e sentindo a ameaça sobre sua soberania, condenasse o sexo feminino como algo maligno e perigoso:

Não é por acaso que em muitas civilizações os cuidados dos mortos e os rituais funerários cabem às mulheres. Elas eram consideradas muito mais ligadas do que o homem ao ciclo - o eterno retorno - que arrasta todos os seres da vida para a morte e da morte para a vida. Elas criam, mas também destroem. Daí os nomes incontáveis das deusas da morte. Daí as múltiplas lendas de monstros fêmeas. (DELUMEAU, 1989, p. 312).

É fato que, na cultura erudita medieval, dedicava-se uma "admiração" à mulher, mas essa mesma cultura estipulava um espaço extremamente recluso e imóvel para ela dentro da sociedade, na qual bastava que fosse digna de veneração. Já na cultura popular, ela tinha a possibilidade de ser a curandeira, a parteira, a mulher que, em contato com a natureza, cura e dá a vida. Havia a possibilidade de uma "bruxa boa":

"Historicamente, a bruxa boa era a parteira, a médica, a adivinha ou a feiticeira do 
vilarejo" (FEDERICI, 2017, p. 366). Inclusive, para essa bruxa, "não lhe interessava inspirar medo à comunidade, já que a prática dessas artes era sua forma de ganhar a vida. Ela era, de fato, muito popular, todos a procuravam para ser curados, para que lesse o futuro, para encontrar objetos perdidos ou para comprar poções de amor" (FEDERICI, 2017, p. 367).

Essas questões, porém, poderiam ser interpretadas de outra forma e a bruxa poderia tonar-se má e perigosa. Por ter esse contato com o feminino e a fertilidade, as mulheres que com isso lidavam eram passíveis de sofrer acusações opostas: poderiam ser culpadas de infanticídios, magia negra, rituais de sacrifícios e com fins maléficos. "O medo da bruxa que ataca crianças recém-nascidas ou ainda pequenas era uma das crenças disseminadas nas culturas populares de toda a Europa. No estereótipo geral dessas crenças, a bruxa atacava a criança chupando o seu sangue até que ela morresse" (MALUF, 1993, p. 153). Além disso, havia mulheres pobres que roubavam e mendigavam entre a população, sendo mal vistas e tornando-se suspeitas de praticar artes malignas (FEDERICI, 2017, p. 365). Muitas dessas mulheres eram idosas e sem condições de conseguir algum sustento para si, o que contribui para termos, até hoje, a ideia de uma bruxa como uma mulher velha e pavorosa.

Muitas mulheres acusadas e processadas por bruxaria eram velhas e pobres. Dependiam com frequência da caridade pública para sobreviver. A bruxaria - segundo dizem - é a arma daqueles que não têm poder. [...] Elas encarnavam o saber e a memória da comunidade. A caça às bruxas inverteu a imagem da mulher velha: tradicionalmente considerada uma mulher sábia, ela se tornou um símbolo de esterilidade e de hostilidade à vida. (FEDERICI, 2017, p. 352-353).

Apesar dessas transformações terem acontecido ao longo do tempo com a figura da bruxa, houve uma delas que marcou sua imagem como algo negativo de forma permanente: a associação que a Igreja fez dessa mulher com o Diabo, em uma suposta relação na qual ela obedecia e fazia todas as suas vontades por meio de inumeráveis males à sociedade. Só na Idade Moderna, com a caça às bruxas, a realidade dessa figura histórica foi transformada. Sônia Maluf aponta que, para alguns historiadores, o conceito de bruxaria, antes da Idade Moderna, era algo difuso e impreciso, e 
foi a visão das elites que iniciou um processo de categorização e exposição das, agora nomeadas, bruxas (1993, p. 140-141). Inclusive todos os registros feitos a respeito de bruxaria durante a inquisição compõem-se de "denúncias, acusações, depoimentos e confissões que constam dos processos instaurados nos tribunais eclesiásticos e seculares que julgaram a bruxaria" (MALUF, 1993, p. 141). Assim, uma figura que antes fora dividida entre uma mulher curandeira, parceira da comunidade (em maior parte) e uma figura maléfica, danosa para a comunidade (em menor parte) tornou-se, no imaginário, uma fonte de extremo mal ao ser assim acusada pela Igreja Católica.

A bruxa, agora, tornava-se um bode expiatório para que o Catolicismo afirmasse a sua visão de mundo para a sociedade; uma visão que não deixava espaço para a harmonia com a natureza, para uma crença no maravilhoso e na possibilidade de soluções mágicas para problemas, fossem essas soluções rituais ou até mesmo o uso de plantas medicinais. Assim, construindo essa ideia de que a figura do Demônio era um agente forte e presente na vida real da sociedade, capaz de tentar, danar e corromper o ser humano, a Igreja foi capaz de aumentar seu poder de controle e obediência. Associando o Demônio à bruxa, poderia controlar diversas outras esferas. Dessa forma:

Ao conjurar o demônio, os inquisidores descartaram o animismo e o panteísmo popular, redefinindo, de uma maneira mais centralizada, a localização e a distribuição do poder no cosmos e na sociedade. Assim, paradoxalmente - segundo Parinetto - na caça às bruxas, o diabo funcionava como o verdadeiro servo de Deus [...]. como um oficial de justiça, ou como o agente secreto de Deus, o diabo trouxe a ordem ao mundo, esvaziando-o de influências conflitivas e reafirmando Deus como soberano exclusivo. (FEDERICI, 2017, p. 372).

Finda a caça às bruxas, a ordem cristã havia vencido e de pouco importava 0 caminho que agora a figura da bruxa seguiria. De acordo com Silvia Federici, muitas dessas mulheres continuaram a trabalhar com a adivinhação, encantamentos e outras formas de magia para seu sustento (2017, p. 374). Apesar disso, o estigma estava lançado: a figura da bruxa como uma mulher velha, má e sádica estava marcada na sociedade ocidental. 


\section{A LITERATURA ANTIMITOLÓGICA DE H. P. LOVECRAFT E O CRISTIANISMO}

H. P. Lovecraft foi um escritor norte-americano que viveu durante as primeiras décadas do século XX. Sua obra transita entre o horror, o fantástico e, com frequência menor, a fantasia. Uma marca forte que aparece em diversos de seus contos é uma mitologia criada para dar fundamento às entidades alienígenas e ao funcionamento do universo dentro do conjunto de seu trabalho. Tal mitologia - ou antimitologia consiste na ideia da existência de seres extraterrestres concomitante à humanidade, seres que povoam nosso planeta, como também diversos outros pontos do cosmos. A existência desses seres é, por muitos personagens humanos dentro das obras, entendida como sagrada e, assim, vários deles são tidos por esses personagens como deuses. Cultos e rituais são feitos em motivo de adoração para essas entidades, mas, em contrapartida, seus adoradores nada recebem em troca, uma vez que a existência humana é ou ignorada por esses seres, ou completamente irrelevante.

Em uma análise do conjunto da obra de Lovecraft, unindo informações sobre cada uma dessas entidades, podemos afirmar que são apenas seres vivos como nós, mas que de forma alguma são sagrados. Isso porque eles subvertem muitas das características essenciais de uma mitologia, não se importando com nossa existência - muitas vezes sequer tendo conhecimento dela; não nos proporcionando exemplos de como viver nossas vidas para criarmos valores éticos e morais; por fim, não nos confortando em meio a um universo caótico e sem sentido. Assim, essas entidades vistas como deuses são apenas seres que habitam o universo assim como nós, não sendo sobrenaturais, mas sim desconhecidos ou simplesmente incompreensíveis para a razão humana.

A criação dessa antimitologia tem relação direta com os fundamentos do próprio autor, em relação às diversas religiões existentes. Ele declarava-se ateu e cético, tendo abandonado qualquer crença religiosa ainda na infância. Sua opinião sobre o Cristianismo é particularmente interessante:

A primeira manifestação da minha natureza cética provavelmente ocorreu antes do meu quinto ano, quando me contaram o que eu 
já sabia - que o "Papai Noel" era um mito. A revelação me levou a perguntar por que "Deus" não poderia ser da mesma forma um mito. Pouco tempo depois fui colocado na "classe infantil" da catequese [...] e lá abandonei todos os meus vestígios da fé cristã. $\mathrm{O}$ absurdo dos mitos que eu era instado a aceitar e a lugubridade cinzenta daquela crença como um todo quando comparada à magnificência do maometanismo transformou-me em um agnóstico convicto e fez de mim um inquiridor tão obstinado que recebi permissão para deixar de frequentar a igreja. (LOVECRAFT, 2011, p. 70).

Essa opinião do autor contribuiu para que pouquíssimos elementos da mitologia cristã tivessem espaço em sua obra, ainda que ela tratasse sobre temas mitológicos. Apesar disso, o autor estudou e tinha grande conhecimento a respeito da tradição cristã de onde vivia: Providence, capital do estado de Rhode Island, pertencente à Nova Inglaterra, região mais tradicional e puritana dos Estados Unidos, onde Lovecraft nasceu e viveu a maior parte de sua vida. A história das bruxas de Salem, ocorrida nesta cidade do estado de Massachusetts, no ano de 1692, em muito o interessava. Apesar de se tratar de um evento liderado pela fé cristã, sua história e ocorrências em muito tomavam a atenção do autor.

Uma característica marcante de Lovecraft é a inserção de fatos e pessoas reais em sua obra, com o objetivo de contribuir para um efeito de realidade na experiência do leitor. Ao se deparar com lugares, acontecimentos e pessoas que possa conhecer, a identificação do leitor com o texto/personagem e o consequente efeito de realidade são muito mais efetivos. Cotton Mather foi um autor e ministro puritano da Nova Inglaterra que procurava combater fortemente a magia e a bruxaria, tendo escrito obras sobre o assunto, como Memorable Providences Relating to Witchcraft and Possessions (1689) e Wonders of the Invisible World (1693), tendo sido um dos principais envolvidos nos julgamentos de Salem. Os livros de Mather, assim como o próprio personagem, são mencionados em diversos contos de Lovecraft, ainda que, na maioria das vezes, de forma rápida e sutil. Um desses contos é “Os sonhos na casa da bruxa”, escrito em 1932 e publicado em 1933, que veremos a seguir. 


\section{A BRUXA EM H. P. LOVECRAFT}

"Os sonhos na casa da bruxa" é um conto de Lovecraft que trabalha com a figura da bruxa como personagem central. Aqui propomos analisar de que forma ele representou essa figura histórico-imaginária. A trama desse conto se passa na cidade de Arkham, criada por Lovecraft como uma espécie de duplo ficcional de Salem. Arkham, assim como Salem, está localizada no estado de Massachusetts e possui um histórico de bruxaria criado pelo autor. A trama é narrada em terceira pessoa, fato não muito característico nos contos de Lovecraft, que, em sua maioria, são relatados por um narrador-personagem.

No caso do conto aqui analisado, temos um narrador distante que acompanha o personagem principal, Walter Gilman, um estudante da Miskatonic University, localizada em Arkham e também criada por Lovecraft. Por motivo de seus estudos, Gilman aluga um pequeno quarto no sótão de uma pensão; quarto este que estivera abandonado por muito tempo, devido à sua fama: ele fora o quarto de Keziah Mason, uma bruxa que fugiu de seu julgamento em Salem, em 1692. Sua fuga teria sido inexplicável e motivo de indagações até os tempos presentes:

[...] o carcereiro havia enlouquecido e balbuciava sobre uma coisinha peluda de presas brancas que correra para fora da cela de Keziah, e nem mesmo Cotton Mather pôde elucidar as curvas e ângulos lambuzados na pedra cinzenta com algum fluido vermelho e viscoso (LOVECRAFT, 2017, p. 83-84).

Vemos que a história é iniciada com um plano de fundo para a bruxa: ela vivera em Salem, localização real, sendo julgada por Cotton Mather, um personagem real. Isso nos permite supor que ela conheceu e viveu todo o contexto da perseguição às bruxas da Nova Inglaterra, especialmente de Salem. Em 1692, data real que Lovecraft utilizou para sua fuga, a região já havia passado por uma longa história de perseguições:

A partir da década de 1640 a Nova Inglaterra começou a sofrer. O primeiro enforcamento de uma bruxa na Nova Inglaterra ocorreu em Connecticut em 1647; um certo número de outros casos foram levados ao tribunal nas décadas de 1640 a 1680, e houve enforcamentos 
em Providence em 1662. Os líderes intelectuais da Nova Inglaterra defendiam a crença em bruxas. [...] Os mais memoráveis e bem-documentados julgamentos por bruxaria na América ocorreram em Salem em 1692. (RUSSEL, 1993, p. 87).

Definir esse plano de fundo histórico para o conto permite que compreendamos o contexto no qual a narrativa se passará; um contexto com uma população que acredita na bruxaria e em todas as superstições relacionadas a ela. Gilman, portanto, aluga o quarto ciente do que está fazendo e recebe contestações de seus vizinhos na pensão, que recomendam que ele não ocupe aquele local profano. Esse, contudo, é seu grande interesse: além de estudar física quântica e cálculo não euclidiano, Gilman mistura-os ao folclore e às lendas:

Gilman era proveniente de Harverhill, mas foi somente depois de entrar na faculdade em Arkham que ele começou a ligar seus estudos de matemática com as lendas fantásticas da antiga magia. Alguma coisa na atmosfera da provecta cidade agiu de maneira obscura em sua imaginação. (LOVECRAFT, 2017, p. 84).

Após ter o que considera um acesso de febre cerebral, Gilman começa a ver a bruxa em seus sonhos. Durante esses acessos, em um primeiro momento Gilman se vê em realidades distantes e, em sua opinião, para além do limite da sanidade. Após algumas noites de sonhos com esses lugares inimagináveis, Gilman começa, por fim, a receber a presença da bruxa e de seu familiar, chamado Brown Jenkin.

Keziah Mason segue todos os estereótipos de bruxa que sobreviveram ao século XX: ela é descrita da seguinte forma:

A velha maligna era agora de uma nitidez diabólica, e Gilman sabia que era a mesma que o havia assustado nos bairros pobres. Suas costas curvadas, o longo nariz e o queixo murcho eram inconfundíveis, e seus trajes castanhos sem corte definido eram tais como ele se recordava. A expressão no rosto dela era de medonha malevolência e exultação, e quando ele despertava, podia recordar uma voz crocitante que o persuadia e ameaçava. (LOVECRAFT, 2017, p. 91).

Não apenas a visão da velha e suas impressões por Gilman mostram que ela é 
uma "bruxa má", como também todas as suas ações durante a história. Ela se encaixa no estereótipo físico da bruxa má, velha e maligna. Outra marca característica que Keziah apresenta é a figura do familiar: um pequeno animal que acompanha a bruxa em seus afazeres. De acordo com Silvia Federici, mulheres acusadas de bruxaria eram comumente associadas a algum tipo de bestialidade, o que justificava a parceria com um animal; assim, elas eram acusadas de guardar "uma série de animais - "diabinhos" ou "familiares" - que as ajudavam nos seus crimes e com os quais mantinham uma relação particularmente íntima. Eram gatos, cachorros, lebres, sapos" (FEDERICI, 2017, p. 353).

Brown Jenkin, o familiar de Keziah, é descrito como uma espécie de híbrido entre um rato e algo semelhante a um humano: "testemunhas diziam que ele tinha pelos longos e a forma de um rato, mas que seus dentes afiados e sua face barbada eram diabolicamente humanos, enquanto suas patas eram pequeninas mãos" (LOVECRAFT, 2017, p. 87). A criatura acompanha Keziah em todas as suas artimanhas e aterroriza os moradores da pensão, que constantemente dirigem sua opinião a Gilman. De acordo com esses testemunhos, "ele transportaria mensagens entre a velha Keziah e o diabo, e era nutrido com o sangue da bruxa, que sugava como um vampiro." (LOVECRAFT, 2017, p. 91). Essa é uma das referências que encontramos no conto, que ligam a figura da bruxa ao Diabo e à mitologia cristã; entretanto, ela é a fala de um personagem que relata a lenda que conhece em relação ao animal. Jenkin, sendo um híbrido, configura-se como um monstro sob o olhar da Igreja:

Entre as causas biológicas e humanas dos monstros, há uma que causou grande impressão e que deveria ser considerada como a explicação de grande parte dos monstros. Os híbridos [...] constituem uma das categorias mais importantes: por muito tempo acreditou-se que, "por mistura ou cruzamento de sementes" podiam ser criados seres ao mesmo tempo parecidos com o homem e com o animal. [...] É ainda à Idade Média que pertence o capítulo XXV do mesmo tratado de Paré: "exemplo das coisas monstruosas feitas por demônios e bruxas". (KAPPLER, 1994, p. 325).

No imaginário cristão, uma criatura que não deveria ou poderia existir é fruto de ação demoníaca, inclusive de bruxas. Esse é mais um dos motivos para que os 
personagens do conto se sintam profundamente aterrorizados pela ideia do familiar de Keziah Mason.

Ponto chave para essa questão dentro do texto é o fato de que todas as referências ao Cristianismo e ao Diabo presentes no conto estão embutidas nas falas de personagens religiosos. A população da Nova Inglaterra, em sua maioria e tradicionalmente, é protestante. Entretanto, os personagens que vivem na pensão e interagem com Gilman são estrangeiros católicos e é de acordo com os princípios de sua fé que constroem sua visão da bruxa. De acordo com Alfredo Bronzato da Costa Cruz (2017, p. 114):

O catolicismo romano está presente na América do Norte desde os séculos XV e XVI, mas a hegemonia cultural protestante eventualmente fez com que esta religião fosse associada a elementos estrangeiros - como o Sr. Dombrowski, o senhorio polonês de Gilman, Joe Mazurewicz e Paul Choynski, seus inquilinos e conterrâneos e o Sr. Desrochers, o franco-canadense que morava no quarto logo abaixo daquele alugado pelo desafortunado estudante.

Um exemplo dessa visão cristã da bruxa está na fala de Joe Mazurewicz:

Mazurewicz contara histórias longas e incoerentes sobre o fantasma da velha Keziah e a criatura peluda, farejadora e de presas afiadas, e dissera que certas vezes era tão assombrado com tanta perversidade que somente seu crucifixo de prata - que lhe fora dado com esse propósito pelo padre Iwanicki, da igreja de St. Stanislaus podia trazer-lhe alívio. Agora ele rezava porque o Sabá das Feiticeiras estava se aproximando. A véspera do primeiro de maio era a Noite de Walpurgis, quando os mais negros males do inferno vagavam pela terra e todos os escravos de Satã se reuniam para praticar ritos e façanhas inomináveis. (LOVECRAFT, 2017, p. 91).

Fica claro, por esse trecho e outros como esse, que, no imaginário dos personagens católicos do conto, Keziah é uma bruxa em todos os quesitos, como estabelecido pelo Cristianismo: uma escrava do Diabo, maligna e sujeita aos seus desejos. O narrador, entretanto, não deixa de demonstrar o quanto essas pessoas eram apegadas a superstições e impressionáveis: "aquelas pessoas simples estavam sempre 
prontas para imaginar ter visto qualquer coisa estranha sobre a qual ouviram falar" (LOVECRAFT, 2017, p. 100).

Durante todo o conto, Lovecraft faz um jogo entre as teorias cristãs em relação à bruxa, sua própria mitologia e os verdadeiros propósitos da personagem. Ao longo da narrativa e apesar das opiniões dos personagens, vemos que Keziah, mesmo sendo maligna e tendo todos os traços caricatos da bruxa, é uma cientista e matemática. Sua fuga de Salem se deu justamente por meio da viagem entre dimensões espaciais, arte que ela agora dominava por completo. Entre os diversos diálogos a respeito do assunto que Gilman teve com um colega de faculdade, eles chegam as ideias sobre a bruxa, que interligam a ciência com a magia:

Falaram sobre a velha Keziah Mason, e Elwood concordou que Gilman tinha um bom fundamento científico para pensar que ela devia ter topado com informações estranhas e significativas. Os cultos secretos aos quais essas bruxas pertenciam com frequência guardavam e transmitiam segredos de éons passados e esquecidos; e não era de modo algum impossível que Keziah tivesse de fato dominado a arte de atravessar portões dimensionais. A tradição enfatiza a inutilidade de barreiras materiais para deter os movimentos de uma bruxa; e quem pode dizer o que subjaz às velhas histórias de cavalgadas em cabo de vassoura através da noite? (LOVECRAFT, 2017, p. 102).

$\mathrm{O}$ argumento dos estudantes que procuram explicar a bruxa de Lovecraft demonstra que, portanto, ela se assemelha muito à bruxa curandeira e mágica dos tempos prévios à Inquisição. Se, de acordo com a História, uma bruxa era uma mulher que tinha uma proximidade com a natureza e dominava algumas artes relacionadas a ela, como a biologia e a botânica, Lovecraft apresenta uma bruxa que domina outra dessas artes: a matemática. Por meio de argumentos científicos, Lovecraft infere que muitas das lendas relacionadas às bruxas são fruto de técnicas e cálculos científicos, por exemplo o voo em vassouras. Neste conto, magia e ciência se mesclam em um movimento no qual se complementam e não se dissociam. O narrador afirma que Gilman:

[...] queria estar no edifício onde algumas circunstâncias haviam, de maneira mais ou menos abrupta, fornecido a uma velha mulher do século XVII alguma percepção de profundidades matemáticas 
que talvez superassem as mais modernas descobertas de Planck, Heisenberg, Einstein e Sitter. (LOVECRAFT, 2017, p. 85).

Keziah, além de ser uma bruxa, é também uma cientista e isso Gilman conhecerá de perto durante suas viagens oníricas. Nesse conto de Lovecraft - algo que não costuma acontecer - encontramos uma mescla de ciência e magia na qual essas não se contradizem, mas são apenas diferentes formas de se ver ou abordar um determinado assunto:

O professor Upham gostou particularmente de sua demonstração do parentesco da alta matemática com certas fases da tradição mágica transmitidas ao longo de eras desde uma inefável antiguidade - humana ou pré-humana - cujo conhecimento do cosmos e de suas leis era maior do que o nosso. (LOVECRAFT, 2017, p. 90).

Vemos, no conto, argumentos que justificam a bruxa como uma bruxa cristã e associada ao Diabo, argumentos estes nas falas dos personagens católicos; vemos, também, argumentos que demonstram que a bruxa é uma matemática, que possui controle sobre uma porção da natureza para além do resto da humanidade, não tendo relação alguma com demônios. Vemos, entretanto, alguns argumentos que deixam as arestas desses pontos de vista borradas. $\mathrm{O}$ trecho a seguir, que relata o que Gilman viu em uma de suas experiências, deixa algumas questões em ambiguidade:

Ele devia encontrar o Homem Negro, e ir com eles todos ao trono de Azathoth, no centro do caos derradeiro. Foi isso o que ela disse. Ele deveria assinar com seu próprio sangue o livro de Azathoth e adotar um novo nome secreto. (LOVECRAFT, 2017, p. 91-92).

Essa pequena frase oferece dois elementos que devem ser analisados. Primeiramente, quem seria o Homem Negro que acompanharia Gilman até Azathoth? Suas indagações mostram essa ambiguidade:

Velhas lendas são nebulosas e ambíguas, e em tempos históricos todas as tentativas de cruzar aberturas proibidas parecem complicadas por estranhas e medonhas alianças com seres e mensageiros exteriores. Havia a figura imemorial do agente ou mensageiro de po- 
deres ocultos e terríveis - o "Homem Negro" do culto das feiticeiras e o "Nyarlathotep" do Necronomicon. (LOVECRAFT, 2017, p. 102).

O Homem Negro pode, por um lado, ser alguma figura sombria do universo lovecraftiano, até mesmo o próprio Nyarlathotep, que é mencionado, identificado como um deus do caos e enganador da humanidade. Por outro lado, essa figura pode ser identificada com o Diabo. Historicamente, muitas vezes o Diabo era descrito dessa forma por mulheres acusadas de bruxaria no Novo Mundo; inclusive mencionavam seu comparecimento às reuniões de bruxas e seu papel era muito parecido com aquele que ela instrui Gilman a fazer: "as bruxas frequentavam uma sociedade secreta em que o Diabo comparecia como um homem negro e as batizava em seu nome. Repartiam um pão negro e repugnante de comunhão, davam guarida a demônios em forma de animais" (RUSSEL, 1993, p. 88). Considerando esse relato histórico dos eventos acontecidos em Salem, abre-se espaço para uma interpretação na qual o Homem Negro mencionado por Keziah pode ser, de fato, o Diabo. Os demônios em formas de animais, ademais, podem ser identificados com os familiares e, no caso, Brown Jenkin. Esse dado histórico, entretanto, nos mostra que essa menção de um homem negro como mensageiro de um deus maligno provavelmente é apenas um traço cultural incorporado por Lovecraft e não deve ser diretamente ligado ao Diabo:

O destino comum das bruxas europeias e de seus súditos coloniais está mais bem demonstrado pelo crescente intercâmbio, ao longo do século XVII, entre a ideologia da bruxaria e a ideologia racista que se desenvolveu sobre o solo da conquista colonial e do tráfico de escravos. O diabo era representado como um homem negro e os negros eram tratados cada vez mais como diabos. (FEDERICI, 2017, p. 363).

Lovecraft demonstra, em alguns de seus contos, um racismo de forma mais ou menos acentuada. A inserção desse personagem, assim retratado, nesse conto torna-se, portanto, inconclusiva à sua significação.

Keziah menciona Azathoth como o deus a quem serve. Azathoth é a entidade lovecraftiana considerada o centro de tudo e o criador do universo. Apesar desses feitos, o ser é descrito como uma massa disforme e idiótica, sem propósitos para com 
o mundo ou consigo mesmo. O fato de Keziah mencioná-lo elucida que a história se encaixa no mesmo universo que outros contos de Lovecraft, reunidos no chamado Cthulhu Mythos, ou seja, os contos que possuem esse plano de fundo intergaláctico em comum. Isso faz com que a ideia do Diabo dentro da obra seja enfraquecida, sendo, no final das contas, possivelmente apenas a interpretação dos personagens.

Outro ponto que leva a respostas inconclusivas a respeito da mitologia do conto é uma passagem na qual Gilman é atacado pela bruxa. Durante esse ataque, ele retira de dentro da blusa o crucifixo que havia ganhado de Mazurewicz, que causa uma reação surpreendente na velha:

Ele sentiu o atrito da corrente do crucifixo barato no seu pescoço e, em meio à situação de perigo, perguntou-se como a visão do objeto afetaria a criatura maligna. [...] ele alcançou debilmente o interior de sua camisa e puxou o símbolo de metal rompendo a corrente e liberando-o. À visão do objeto a bruxa pareceu golpeada pelo pânico, e seu aperto relaxou por tempo suficiente para que Gilman tivesse uma chance de interrompê-lo por completo. (LOVECRAFT, 2017, p. 107).

Esse é um dos acontecimentos da história que mais levantam questionamentos por parte dos pesquisadores da obra de Lovecraft. Se a velha não possuía relação com o Cristianismo, mas sim com ritos muito mais antigos e desconhecidos, por que o objeto lhe teria causado essa reação? Alfredo Bronzato da Costa Cruz faz um levantamento sobre as diferentes opiniões de pesquisadores sobre o assunto:

Alguns sustentaram que isso é um elemento de menor importância, mesmo ridículo, especialmente caso se considere que Lovecraft era ateu desde jovem; uma mera sobrevivência, talvez inconsciente, de estereótipos presentes em algumas estórias de terror mais antigas. Outros afirmaram que a bruxa ficou simplesmente surpresa ao ver que um objeto de metal afiado (sic) estava sendo empurrado em direção a seu rosto; enquanto um terceiro grupo aventa a possibilidade de que, com este pânico, Lovecraft estaria indicando (em possível denúncia) o quanto a velha havia sido psicologicamente danificada pelas torturas que os cristãos lhe infligiram no século XVII. (CRUZ, 2017, p. 125). 
O verdadeiro motivo e o significado dessa cena dentro da história são, assim, inconclusivos. Pela lógica interna do texto, contudo, seria muito improvável que o objeto pudesse causar algum mal sobrenatural à bruxa, já que ela se diz sujeita a Azathoth, deus idiota sem relação alguma com o Cristianismo ou seus objetos sagrados. Acreditamos que tanto a simples ameaça de algo que pudesse feri-la - o que de fato acontece, já que Gilman a estrangula com a corrente do crucifixo - quanto as ideias mais imaginativas, que relacionam sua reação a algum dano psicológico causado por torturas sejam mais válidas.

Há, ainda, outros elementos no conto que atam Keziah Mason ao estereótipo da bruxa: como vimos anteriormente, bruxas eram constantemente acusadas pela morte e o desaparecimento de crianças. Isso é algo que ocorre próximo ao fim da trama, quando Keziah, junto a um Gilman em estado de confusão entre o sonho e a realidade, sequestra uma criança para realizar um ritual de sangue. A cena do sacrifício é também bastante caricata:

Sobre a mesa jazia uma pequena figura alva - um menino ainda bebê, despido e inconsciente - enquanto do lado oposto postava-se a monstruosa velha de olhar malicioso, com uma reluzente faca com um cabo de forma grotesca na mão direita e uma bacia pálida de metal moldada em estranhas proporções, coberta de desenhos curiosamente cinzelados e com delicadas asas laterais, à sua esquerda. (LOVECRAFT, 2017, p. 106).

Essa cena dialoga com todo o histórico da bruxa, relacionado ao desaparecimento, morte e doenças de crianças desde a Idade Média. Mais do que isso, ela afirma que esses rituais são reais para Keziah e fundamentais para sua mitologia e desígnios particulares, enfatizando o estereótipo da bruxa má. Além de matar crianças, Keziah possui grande força, conseguindo pressionar fortemente o pescoço de Gilman no momento de seu embate, surpreendendo o rapaz. Essa força sobrenatural era mais um dos elementos que denunciavam uma bruxa durante os julgamentos de Salem: "A segunda variedade de prova era da natureza empírica: o uso de um poder sobrenatural. A vítima podia demonstrar uma força descomunal" (RUSSEL, 1993, p. 91).

Como pudemos observar, o conceito da bruxa transformou-se com o passar 
dos anos, passando de uma mulher curandeira e conhecedora de rituais mágicos a uma mulher maligna e escrava do Diabo. Apesar de termos personagens no conto "Os sonhos na casa da bruxa" que acreditam que Keziah Mason seja uma bruxa do segundo tipo - submissa ao Diabo -, Lovecraft realiza um resgate da bruxa anterior, a conhecedora da natureza, renovando-a como uma cientista de uma área não pensada antes, a matemática. Apesar de cientista, ela não deixa de ser religiosa, mas o funcionamento de sua religiosidade é um mistério apenas parcialmente apresentado no conto; e, apesar dessa cientificidade, ela não deixa de ser má, construída de uma forma completamente negativa.

Lovecraft tentou, nessa obra, reescrever a figura da bruxa sob parâmetros modernos de ciência, mas não conseguiu - ou não quis - evitar estereótipos dispensáveis e redutivos em sua descrição da personagem. O conjunto da obra de Lovecraft apresenta pouquíssimas personagens femininas, sendo Keziah uma das mais fortes entre essas personagens, entretanto sua essência não é construída de forma ambígua e aprofundada. A mulher aparenta ser de todo má, apesar de sua racionalidade, algo bastante raro em personagens lovecraftianos, comumente construídos além da dualidade bem-mal.

Observamos, a partir dessa ideia, uma possível dificuldade ou resistência de Lovecraft em desenvolver personagens femininas, quase sempre meras coadjuvantes ou figuras más e estereotipadas.

Além de Keziah, outra importante personagem feminina de Lovecraft é Lavínia Whateley, do conto "O horror de Dunwich" (1929), também semelhante a uma bruxa e participante de rituais pagãos, mãe de uma figura demoníaca e ela mesma desprezível, mas bem menos desenvolvida no conto. Em Lovecraft, não temos personagens femininas cientistas ou acadêmicas, como a grande maioria de seus protagonistas; as mulheres são sempre personagens secundárias e maléficas, em contraste com esses narradores detentores de conhecimento e bom senso. Keziah Mason, portanto, é uma bruxa renovada, mas não o suficiente. 


\section{REFERÊNCIAS}

CRUZ, Alfredo Bronzato da Costa. Algumas imagens do catolicismo nos contos de H. P. Lovecraft. Revista Abusões. Rio de Janeiro, n. 04, n. 04, ano 03, p. 100-152. 2017. DELUMEAU, Jean. Os agentes de Satã III: a mulher. In: História do medo no Ocidente. São Paulo: Cia. Das Letras, 1989.

FEDERICI, Silvia. A grande caça às bruxas na Europa. In: Calibã e a bruxa. São Paulo: Elefante, 2017.

KAPPLER, Claude, A noção de monstruosidade. In: Monstros, Demônios e Encantamentos no Fim da Idade Média. São Paulo: Martins Fontes, 1994.

LOVECRAFT, H. P. A confissão de um cético. In: A cor que caiu do espaço. São Paulo: Hedra, 2011.

LOVECRAFT, H. P. Os sonhos na casa da bruxa. In: Contos reunidos do mestre do horror cósmico. São Paulo: Ex Machina, 2017.

MALUF, Sônia. As raízes na bruxaria europeia medieval e moderna. In: Encontros Noturnos. Rio de janeiro: Rosa dos tempos, 1993.

RUSSEL, Jeffrey Burton. Bruxaria nas colônias americanas. In: História da feitiçaria. Rio de Janeiro: Campus, 1993. 